\title{
Antiinflammatory activity of two Ayurvedic formulations containing guggul
}

In the traditional systems of medicine, many polyherbal formulations are being prescribed for inflammatory conditions. ${ }^{[1]}$ Although these preparations have been claimed to have antiinflammatory activity and some of the individual ingredients of the formulations have been shown to have antiinflammatory activity, ${ }^{|2|}$ the activity of the formulations has not been experimentally evaluated. We evaluated the antiinflammatory activity of two important polyherbal Ayurvedic formulations viz., chandraprabha vati and Maha yogaraja guggulu in rat paw edema model. Chandraprabha vati (CPV) is a classical polyherbal formulation, which consists of 37 ingredients of plant and mineral origin and is being widely used for various disorders such as anemia, pain, indigestion and renal calculi. ${ }^{11}$ Maha yogaraja guggulu (MYG) is a classical polyherbal formulation consisting of 31 ingredients of plant and mineral origin and is being widely used for anal fistula, leprosy and in the treatment of edema ${ }^{1}$. To the best of our knowledge, the pharmacological activity of these formulations has not been reported.

CPV and MYG used in the present study were prepared by an Ayurveda practitioner specialized in the preparation of classical formulations (Rasa shastra) and were labelled as PS (prepared samples). Commercial samples were procured from local market and were labelled as MS1 and MS2.

Fifty vati (round pills) of each sample were powdered and from that $20 \mathrm{~g}$ powder was extracted under reflux with methanol $(4 \times 50 \mathrm{ml})$ for $15 \mathrm{~min}$. The extracts were filtered, pooled and the solvent was evaporated completely under reduced pressure. Preliminary phytochemical analysis of the sample extract was carried out for the presence of different chemical groups such as phenolics, tannins, steroids/ terpenoids, coumarins and alkaloids. TLC fingerprint profiles were developed for the methanolic extract and co-TLC was done with marker compounds viz., Z-guggulsterone, piperine, berberine, gallic acid, ellagic acid and $\beta$-sitosterol.

For the evaluation of antiinflammatory activity of the formulations, carrageenan-induced rat paw edema model was used. ${ }^{[3]}$ The protocol was approved by the Institutional Animal Ethics Committee. Male Sprague Dawely rats of either sex, weighing 150 - $200 \mathrm{~g}$ were housed (three rats per cage) under well-controlled conditions of temperature $\left(22 \pm 2^{\circ} \mathrm{C}\right)$, humidity $(55 \pm 5 \%)$ and $12 \mathrm{~h}$ light/dark cycle. Animals were fed a standard pellet diet with water ad libitum. Overnight fasted animals were divided into three groups, each consisting of six animals. Sample extracts in $2 \%$ gum acacia were given to the treatment group in a dose of 100,250 and $500 \mathrm{mg} / \mathrm{kg}$, b.w., one hour before injecting carrageenan. Inflammation was induced by injecting $0.1 \mathrm{ml}$ of $1 \%$ carrageenan in normal saline in right hind paw of the rat. Paw volume was measured by plethysmometer at 0 and $3 \mathrm{~h}$ after the carrageenan injection.
Activity was expressed in terms of percent inhibition of paw oedema compared to untreated control. Ibuprofen $100 \mathrm{mg} / \mathrm{kg}$ suspended in $2 \%$ gum acacia was used as positive control. For the commercial sample, only a single dose of $500 \mathrm{mg} / \mathrm{kg}$ dose was given.

The experimental data were expressed as mean $\pm \mathrm{SD}$. The significance of difference among the various treated groups and positive control group were analysed by means of oneway ANOVA followed by Tukey's post-hoc test. $\mathrm{P}<0.05$ was considered statistically significant.

Present study deals with preliminary phytochemical testing for the presence of different chemical groups, cochromatography with marker compounds and testing the two formulations for antiinflammatory activity. Preliminary phytochemical testing showed the presence of phenolics, tannins, steroids/terpenoids and alkaloids. The presence of phenolics and tannins assumes importance since the role of free radicals in inflammation cascade is well known and phenolics are established to have free radical scavenging activity. ${ }^{|4|}$ Co-TLC with marker compounds showed the presence of Z-guggulsterone (from the major ingredient, guggulu), piperine, berberine, gallic acid, ellagic acid and Bsitosterol. All these compounds have been reported to have antiinflammatory activity. ${ }^{[5-\mid 8]}$

CPV and MYG showed dose-dependent antiinflammatory activity with a maximum of $45 \%$ and $49 \%$ in paw edema, respectively, at a dose of $500 \mathrm{mg} / \mathrm{kg}$. Prepared samples showed significantly better activity as compared to the commercial samples $(\mathrm{P}<0.01)$. [Table 1]

\section{Table 1}

Effect of methanolic extract of chandraprabha vati (CPV) and maha yogaraja guggulu (MYG) on carrageenan-induced rat paw edema

\begin{tabular}{lccc}
\hline Group & Dose $(\mathbf{m g} / \mathbf{k g})$ & \multicolumn{2}{c}{$\%$ Inhibition of paw edema } \\
\cline { 2 - 3 } & & $\boldsymbol{C P V}$ & \multicolumn{1}{c}{$\boldsymbol{M Y G}^{*}$} \\
\hline PS & 100 & $18 \pm 0.6$ & $19 \pm 0.3^{\mathrm{a}}$ \\
& 250 & $32 \pm 0.2$ & $36 \pm 1.2^{\mathrm{a}}$ \\
MS1 & 500 & $45 \pm 1.1$ & $49 \pm 0.7^{\mathrm{a}}$ \\
MS2 & 500 & $43 \pm 0.5^{\mathrm{b}}$ & $40 \pm 0.3^{\mathrm{b}}$ \\
Ibuprofen & 500 & $37 \pm 0.9^{\mathrm{b}}$ & $46 \pm 0.2^{\mathrm{b}}$ \\
& 100 & $65 \pm 0.4$ &
\end{tabular}

${ }^{*}$ Mean $\pm S D, n=6$. PS - prepared sample; MS1 and MS2 - market samples. aSignificantly different from CPV at same dose level $(P<0.01)$. ${ }^{b}$ Significantly different from corresponding prepared samples at same dose level $(P<0.01)$. 
Plant-based drugs and formulations are in use since ancient times. However, very little work has been reported on the pharmacological evaluation of the classical formulations for the activities claimed in traditional medicine. The above study was an effort to evaluate the traditional claims of the two guggul containing ayurvedic formulations Chandraprabha Vati and Maha yogaraja Guggulu.

M.S. Bagul, H. Srinivasa, N.S. Kanaki, M. Rajani

B.V. Patel Pharmaceutical Education and Research Development (PERD) Centre,

Thaltej-Gandhinagar highway,

Thaltej, Ahmedabad - 380 054, India

E-mail: rajaniflower@yahoo.com

\section{References}

1. The Ayurvedic Formulary of India, Part-I. Government of India, Ministry of Health and Family Welfare. Department of Indian Systems of Medicine \& Homeopathy New Delhi: 2003.

2. Indian Council of Medical Research. Quality Standards of Indian Medicinal Plants, Vol. 1. New Delhi: 2003.

3. Winter CA, Risley EA, Nuss GW. Carrageenan induced edema in hind paw of the rat as an assay for anti-inflammatory drugs. Proc Soc Exp Biol Med 1962;111:544.

4. Haslam E. Natural polyphenolis (vegetable tannins) as drugs: Possible modes of action. J Nat Prod 1995;59:205.

5. Sosa S, Tubaro A, Loggia RD, Bombardelli E. Anti-inflammatory activity of Commiphora mukul extracts. Pharmacol Res 1993;27:89-90.

6. Arora RB, Kapoor V, Gupta SK, Sharma RC. Isolation of a crystalline steroidal compound from Commiphora mukul \& its anti-inflammatory activity. Indian J Exp Biol 1971;9:403-4.

7. Mujumdar AM, Dhuley JN, Deshmukh VK. Anti-inflammatory activity of piperine. Jpn J Med Sci Biol 1990;433:95-100.

8. Fukuda K, Hibiya $\mathrm{Y}$, Mutoh M. Inhibition of activator protein 1 activity by berberine in human hepatoma cells. Planta Med 1999;65:381-3.

\title{
NATIONAL PHARMACOVIGILANCE PROGRAMME
}

\author{
Ministry of Health \& Family Welfare
}

(Govt. of India)

\section{HELP US ENSURE SAFER MEDICATIONS REPORT ALL ADVERSE DRUG REACTIONS VOLUNTARILY TO YOUR NEAREST ADR MONITORING CENTER}

\section{ZONAL CENTERS}

1. Department of Clinical Pharmacology Seth G..S. Medical College, Mumbai E-mail: dcpkem@vsnl.com

\section{REGIONAL CENTERS}

1. Department of Pharmacology JIPMER, Pondicherry-605 006. E-mail: pvgjipmer@jipmer.edu

2. Department of Clinical Pharmacology T.N. Medical College, Mumbai E-mail: clinpharm@vsnl.com
2. Department of Pharmacology AlIMS

New Delhi

4. Department of Pharmacology IPGMER, Kolkata - 700020. E-mail: sskm_msvp@yahoo.com

5. Department of Pharmacology Lady Hardinge Medical College, New Delhi

3. Department of Pharmacology

Indira Gandhi Medical College, Nagpur

E-mail: drmeenashrivastava@rediffmail.com 